\title{
Estrogenic Activity of Dental Materials and Bisphenol-A Related Chemicals in vitro
}

\author{
Yoshiya HASHIMOTO and Masaaki NAKAMURA \\ Department of Biomaterials, Osaka Dental University, \\ 8-1 Kuzuhahanazono-cho, Hirakata, Osaka 573-1121, Japan
}

Received April 10, 2000/Accepted June 8, 2000

\begin{abstract}
Twenty-eight chemicals used as dental materials and bisphenol-A related chemicals were diluted with DMSO to concentrations ranging from $10^{-7}$ to $10^{-3} \mathrm{M}$ and tested for estrogenicity. Bisphenol-A (BPA), bisphenol-F (BPF) and bisphenol-A-bischloroformate (BPACF) showed estrogenic activity using the yeast two-hybrid system, and BPA, BPF, BPACF and bisphenol-S (BPS) showed estrogenic activity using the fluorescence polarization system. However, none of the remaining chemicals and none of the dental materials showed any activity at concentrations between $10^{-7}$ and $10^{-3} \mathrm{M}$. Although BPA, BPF, BPACF, bisphenol-A-dimethacrylate and BPS showed estrogenic activity in the E-screen test, the remaining chemicals did not. Thus, most of the chemicals showed consistent results, either positive or negative, by the three testing methods, while two chemicals showed conflicting results. Further studies, together with in vivo and epidemiological examinations, are required. Elucidation of the structure-activity relationships of these chemicals is also needed to estimate the estrogenicity of a chemical from its structure.
\end{abstract}

Key words : Estrogenic activity, Bisphenol-A, in vitro

\section{INTRODUCTION}

A significant number of compounds with diverse chemical structures reportedly have estrogenic activity ${ }^{1-3)}$. The chemical structure of one class of endocrine disrupting chemicals that mimic estrogens is known to include two phenolic rings joined through a bridging carbon. These diphenylalkanes have the generic name bisphenols: bisphenol-A (BPA) when the bridging group contains two methyl groups ${ }^{1)}$.

One of the main resin components of dental composites contains 2,2-bis [4-(2hydroxy-3-methacryloxypropoxy)phenyl] propane (Bis-GMA), may be synthesized from BPA and glycidyl methacrylate or, alternately, from the diglycidyl ether of bisphenol-A and methacrylic acid ${ }^{4}$, where the latter process has been adopted by a number of manufacturers. Different manufacturing processes could result in different purity levels of Bis-GMA ${ }^{5}$. These chemicals, as well as polymers with many different chemical structures, have important applications in dental treatment, i.e. as restorative materials, liners, adhesives, oral prosthetic devices, tissue substitutes and rebase materials.

It is necessary to determine whether chemicals for dental use have estrogenic activity. In vitro tests have potential utility for the rapid identification of suspect compounds. Several in vitro assays for measuring estrogen, androgen and dioxin like activity of compounds have been developed. These assays use a variety of end-points, 
including enzyme and gene induction, ligand binding, increased protein expression and cell proliferation and differentiation ${ }^{6)}$. No assay has yet been considered as a reliable in vitro testing method. Further validation processes are needed. Considering the above situation, it is wise to choose candidate methods. The purpose of the present study was to examine the estrogenic activities of dental materials and BPA-related chemicals by three in vitro bioassays based on different principles.

\section{MATERIALS AND METHODS}

The chemicals shown in Table 1 were diluted with DMSO (Lot M9H8197, Nacalai Tesque, Kyoto, Japan) to concentrations ranging from $10^{-7}$ to $10^{-3} \mathrm{M}$. $17 \beta$-Estradiol (E2, Lot ACL1188, Wako, Osaka, Japan) at $10^{-7} \mathrm{M}$ was used as a positive control. All other chemicals were reagent grade, obtained from commercial sources and used without further purification.

We used the yeast two-hybrid system to examine the estrogenic activity of the chemicals according to a technique originally described by Nishikawa et al. ${ }^{7}$ Briefly,

Table 1 Dental materials and bisphenol-A related chemicals used in this study

\begin{tabular}{|c|c|c|c|}
\hline Materials & Code & Manufacturers & Batch \\
\hline Methyl Methacrylate & MMA & Wako $^{1}$ & DLG6719 \\
\hline yl methacrylate & HEMA & Wako & WTQ4257 \\
\hline 2-Methacryloyloxyethyl phenyl phosphate & Phenyl-P & Kuraray $^{2}$ & PP-000853 \\
\hline 4-Methacryloyloxyethyl trimeritic acid & 4-META & Sun Medical $^{3}$ & 97002 \\
\hline 4-Methacryloyloxyethyl trimeritic acid anhydrate & 4-MET & Sun Medical & 98072 \\
\hline 4-Acryloyloxyethyl trimeritic acid & 4-AETA & Shofu ${ }^{4}$ & EF018 \\
\hline -Acryloyloxyethyl tr & 4-AET & Shofu & GJ093 \\
\hline ethylolpropane Trimethacrylate & TMPTMA & Shinnakamura Chem $^{5}$ & $0627 \mathrm{X}$ \\
\hline ethylolpropane Triacrylate & TMPTA & Shinnakamura Chem & $0730 \mathrm{~K}$ \\
\hline Hyc & $\mathrm{HQ}$ & Tokyo KASEI ${ }^{6}$ & M33156K \\
\hline Can & $\mathrm{CQ}$ & Kishida $\mathrm{Chem}^{7}$ & FCW01 \\
\hline lycol dimethacrulat & $1 G$ & Shinnakamura Chem & $0223 \mathrm{~K}$ \\
\hline & $2 \mathrm{G}$ & Shinnakamura Chem & $0730 \mathrm{~K}$ \\
\hline & $3 \mathrm{G}$ & Shinnakamura Chem & SKH4944 \\
\hline & UDMA & Shofu & 50218 \\
\hline $\mathrm{Ne}$ & NPG & Shinnakamura Chem & $0515 \mathrm{~K}$ \\
\hline $\mathrm{Bis}$ & Bis-G & Polyscience ${ }^{8}$ & 470354 \\
\hline Bis & Bis-DMA & Aldrich $\mathrm{Chem}^{9}$ & 06430DG \\
\hline thacryl & Bis-MEPP & Shinnakamura Chem & $0410 \mathrm{~K}$ \\
\hline Bisphenol-A methacryloyloxypolyethoxy phenyl pr & Bis-MPEPP & Shinnakamura Chem & 0824X \\
\hline Bisphenol-A & BPA & Tokyo KASEI & GG01-DK \\
\hline Bispheno & $\mathrm{BPF}$ & Aldrich Chem & $00125 \mathrm{KJ}$ \\
\hline & $\mathrm{BPA}$ & Aldrich Chem & $16424 \mathrm{LS}$ \\
\hline & P-BPA & Aldrich Chem & $12802 \mathrm{HR}$ \\
\hline & $\mathrm{E}-\mathrm{BPA}$ & Aldrich Chem & $05104 \mathrm{EF}$ \\
\hline $\mathrm{Bis}$ & BPAEDA & Aldrich Chem & $12802 \mathrm{HR}$ \\
\hline ycidyl ether & BPDGE & h Chem & $12925 \mathrm{DR}$ \\
\hline Bisphenol-S & BPS & Tokyo KASEI & GG01 \\
\hline
\end{tabular}

${ }^{1}$ Osaka, Japan, ${ }^{2}$ Osaka, Japan, ${ }^{3}$ Moriyama, Japan, ${ }^{4}$ Kyoto, Japan, ${ }^{5}$ Wakayama, Japan,

${ }^{6}$ Tokyo, Japan, ${ }^{7}$ Osaka, Japan, ${ }^{8}$ Illinoi, USA, ${ }^{9}$ Milwaukee, USA 


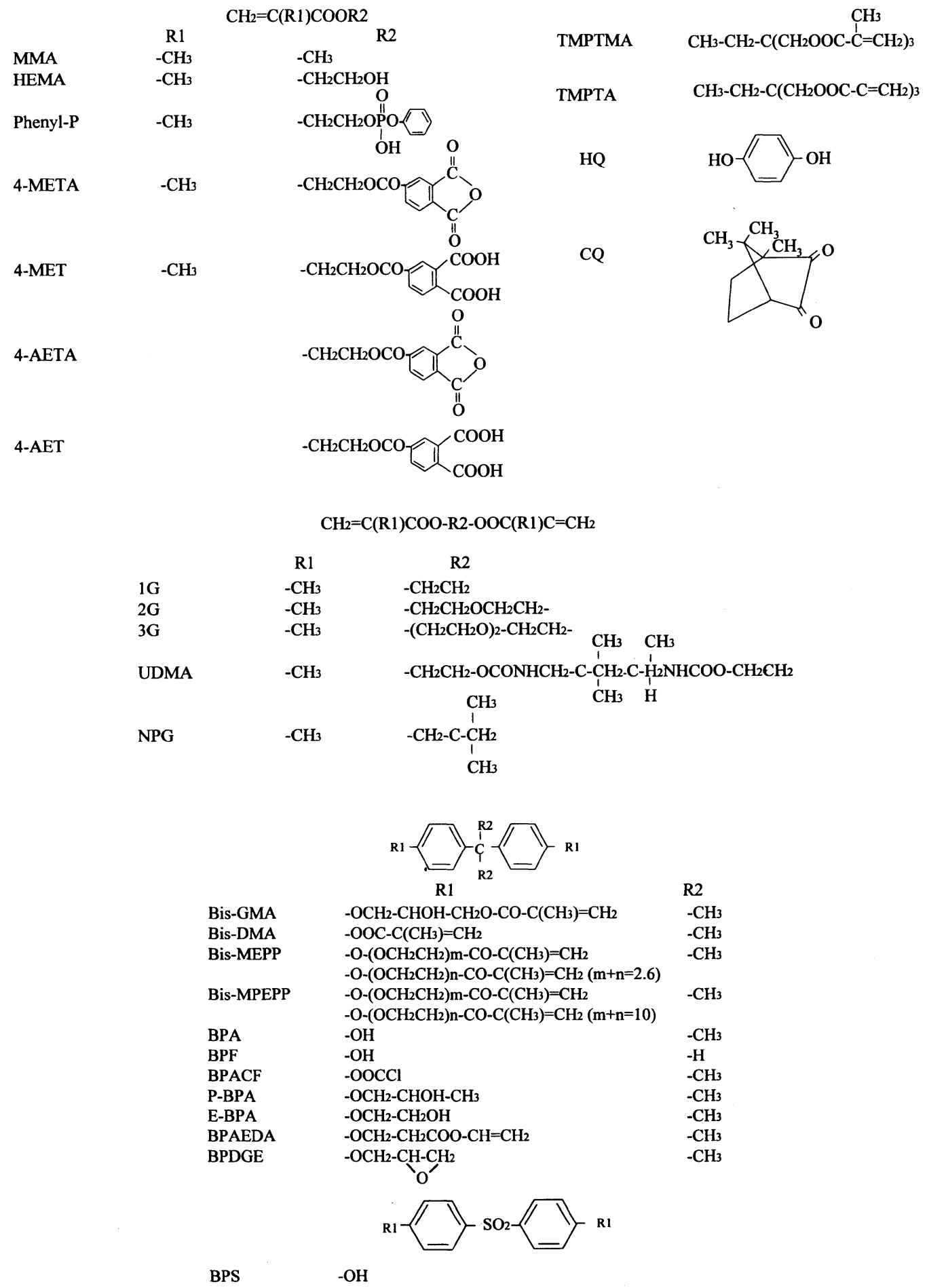

Fig. 1 Chemical structures of dental materials and bisphenol-A related chemicals used in this study. 
yeast transformants were grown overnight at $30^{\circ} \mathrm{C}$ with vigorous shaking in $1 \mathrm{ml}$ of selective medium. Fifty microliters of the overnight culture was then added to 200 $\mu \mathrm{l}$ of fresh medium containing the test chemicals. After the yeasts were cultured for $4 \mathrm{hr}$ at $30^{\circ} \mathrm{C}$, the $\beta$-galactosidase activities were determined. The values are presented as the rate of $\beta$-galactosidase activity divided by that of $10^{-7} \mathrm{M} 17 \beta$-estradiol. For comparison, all chemicals were assessed for estrogenic activity using a fluorescence polarization system according to the technique originally described by Bolger et al. ${ }^{8)}$ with slight modifications. The chemicals were tested for their ability to displace the fluorescent ligand ES1 from the ER-ES1 complex. First, $50 \mu 1$ of the ER-ES1 complex was added to $50 \mu \mathrm{l}$ of screening buffer containing $1 \mu \mathrm{l}$ of the test chemicals, and then negative (the fluorescent ligand ES1 $100 \mu \mathrm{l})$ and positive $(50 \mu \mathrm{l}$ of the ES1-ER complex and $50 \mu \mathrm{l}$ of screening buffer) findings in the absence of a competitor were measured in triplicate. After $60 \mathrm{~min}$ at $25^{\circ} \mathrm{C}$, anisotropy values in each tube were measured on a Beacon 2000 Fluorescence Polarization Instrument (PanVera, Wisconsin, USA) with excitation at $360 \mathrm{~nm}$ and emission at $530 \mathrm{~nm}$. Finally, the values were converted to percent inhibition. In addition, we used MCF-7 cells in the E-screen test of estrogenicity, according to a technique originally described by Villalobos et al. ${ }^{9}$, again with slight modifications. Cells, purchased from the American Type Culture Collection (ATCC), were trypsinized, plated in 96-well plates at initial concentrations of $4 \times 10^{4}$ cells $/ \mathrm{ml}$ in $10 \%$ FBS (Lot AGD6411, Hyclone, Utah, USA) in DMEM (Lot 07591141, Nissui, Tokyo, Japan), and allowed to attach for $24 \mathrm{hr}$; the seeding medium was then replaced with phenol red-free DMEM (Lot 1056152, GIBCO, NY, USA) with $10 \%$ FBS (Lot AHF8529, Hyclone, Utah, USA) that had been treated to remove endogenous steroids, and different concentrations of the test chemicals were added, the assay was completed after $144 \mathrm{hr}$ by removing medium from wells. DMSO served as a control. NR-medium was added to each well, which was then incubated for $3 \mathrm{hr}$. The staining technique was as described by Borenfreund et al. ${ }^{10)}$ Absorbance was measured with a microplate reader equipped with a $540 \mathrm{~nm}$ filter. The values measured, usually in quadruplicate, were averaged, and expressed as the fold increase over the control.

The significance of differences between the different treatment groups was assessed by ANOVA and Scheffe's test. A $p$-value of $<0.05$ was considered significant.

\section{RESULTS}

The relative $\beta$-galactosidase activities of the test chemicals in the two-hybrid system are shown in Figs. 2 a-d. BPA and BPF induced $\beta$-galactosidase activity at concentrations of $10^{-4}$ and $10^{-3} \mathrm{M}$. The highest activity was observed by BPF $(0.66 \pm 0.18)$ among the chemicals that induced $\beta$-galactosidase activity at $10^{-3} \mathrm{M}(\mathrm{p}<0.01)$. BPACF induced $\beta$-galactosidase activity at a concentration of $10^{-4} \mathrm{M}$. However, the remaining 25 chemicals did not induce $\beta$-galactosidase activity at the concentrations tested.

The percent inhibition findings for the test chemicals in the fluorescence polarization system are shown in Figs. 3 a-d. BPA and BPF increased the percent inhibition 


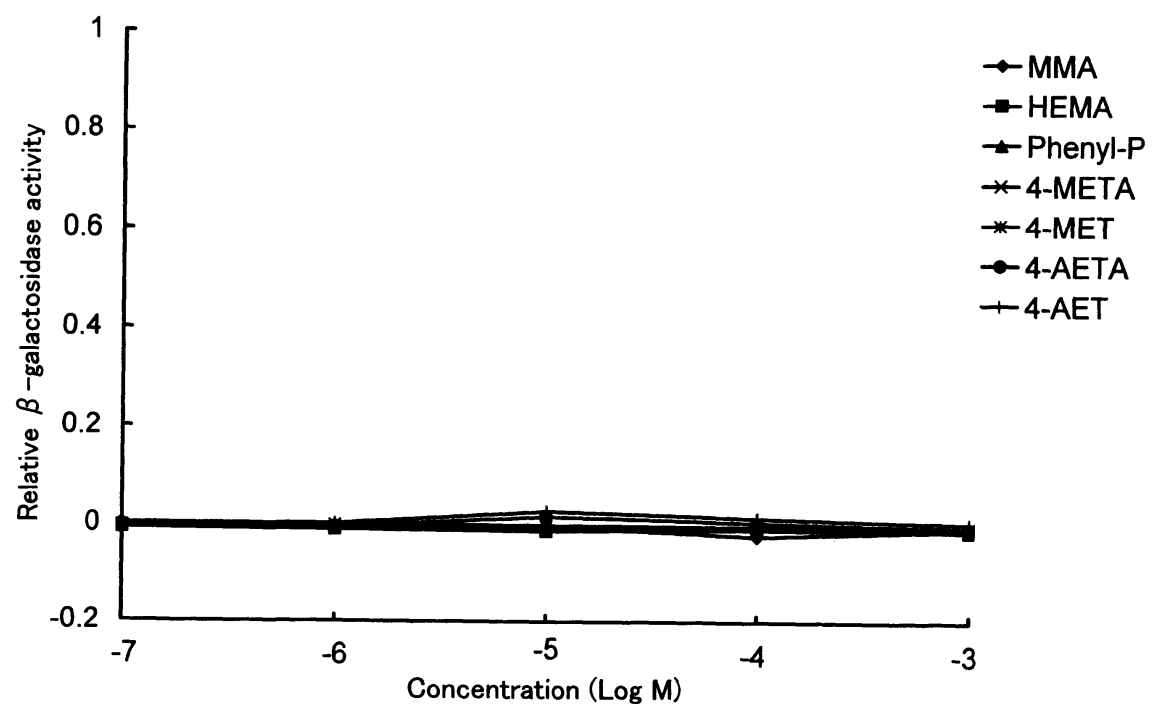

Fig. 2 a

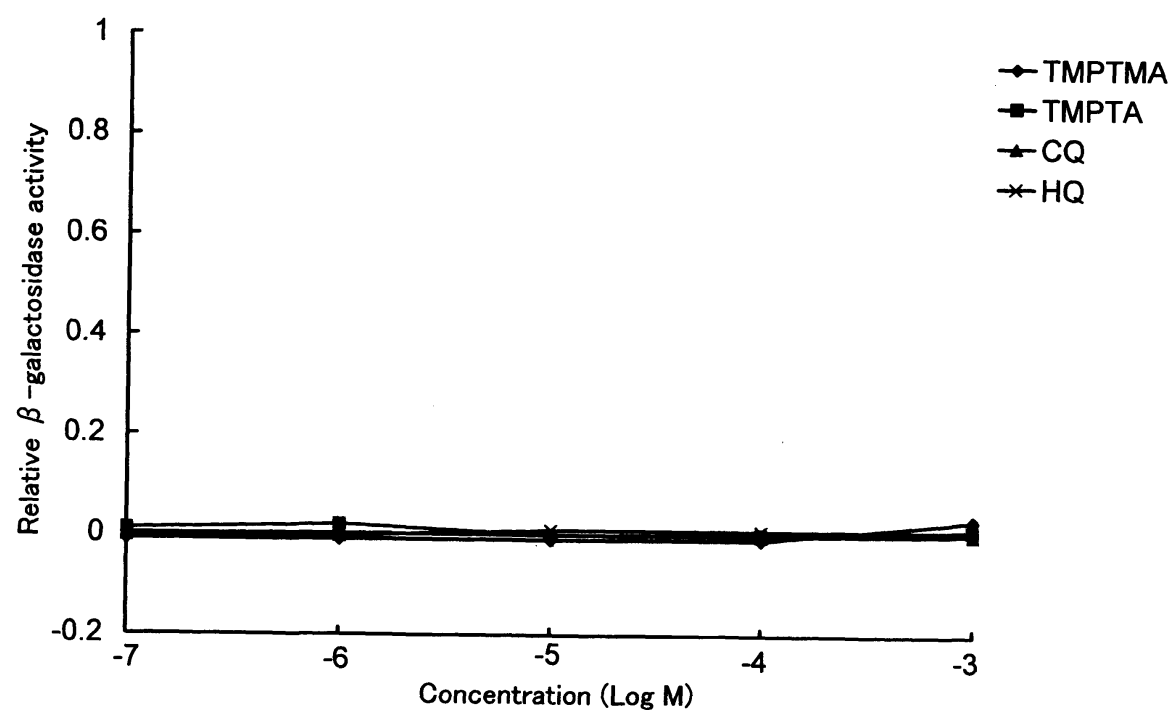

Fig. 2 b 


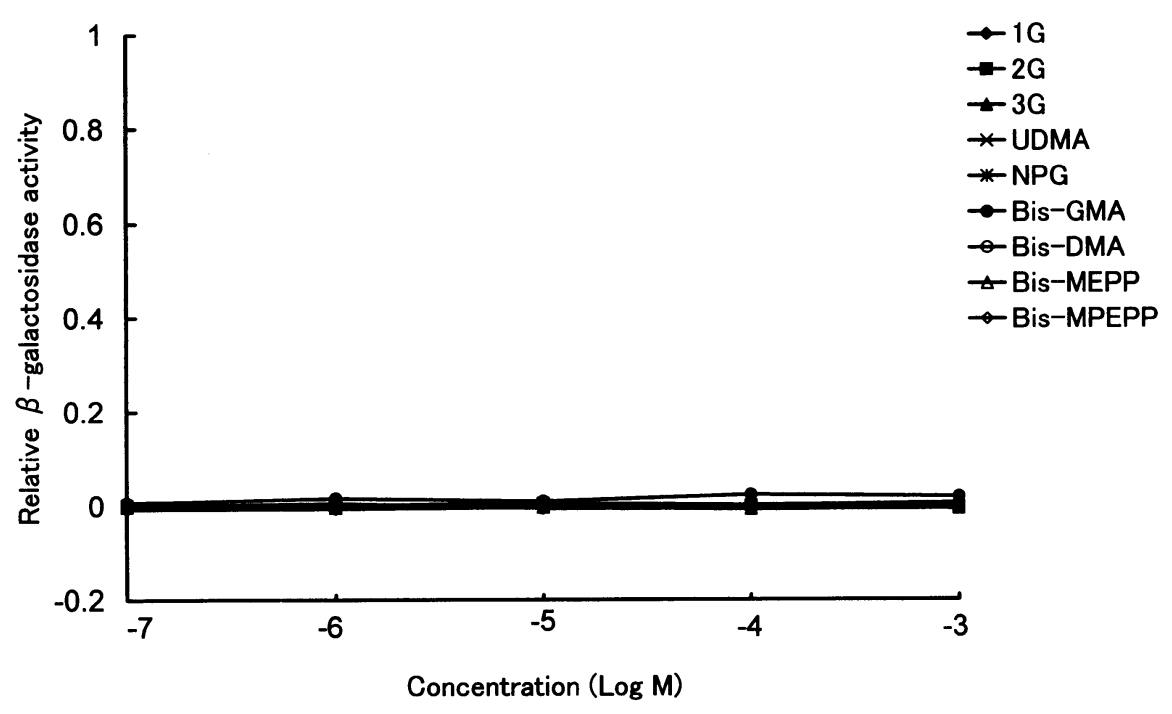

Fig. 2 c

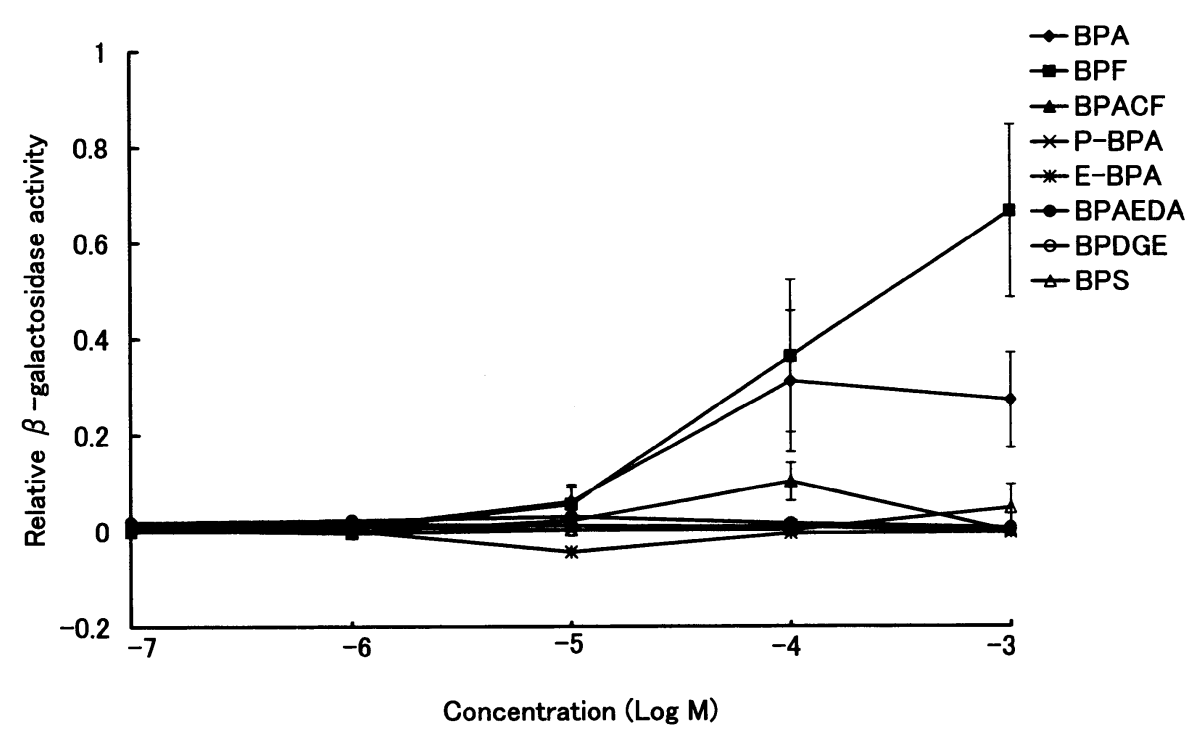

Fig. $2 \mathrm{~d}$

Fig. 2 Dose-response curves of chemicals.

Chemicals were added to yeast cultures in doses ranging from $10^{-7}$ to $10^{-3} \mathrm{M}$. Following $4 \mathrm{~h}$ incubation, the cultures are assayed for $\beta$ galactosidase activity. The values are represented as the rate of $\beta$ galactosidase activity divided by the $\beta$-galactosidase activity at $10^{-7}$ $17 \beta$-estradiol. The error bars except for BPA, BPF, BPACF and BPS were too small and therefore are not shown on the figure. 


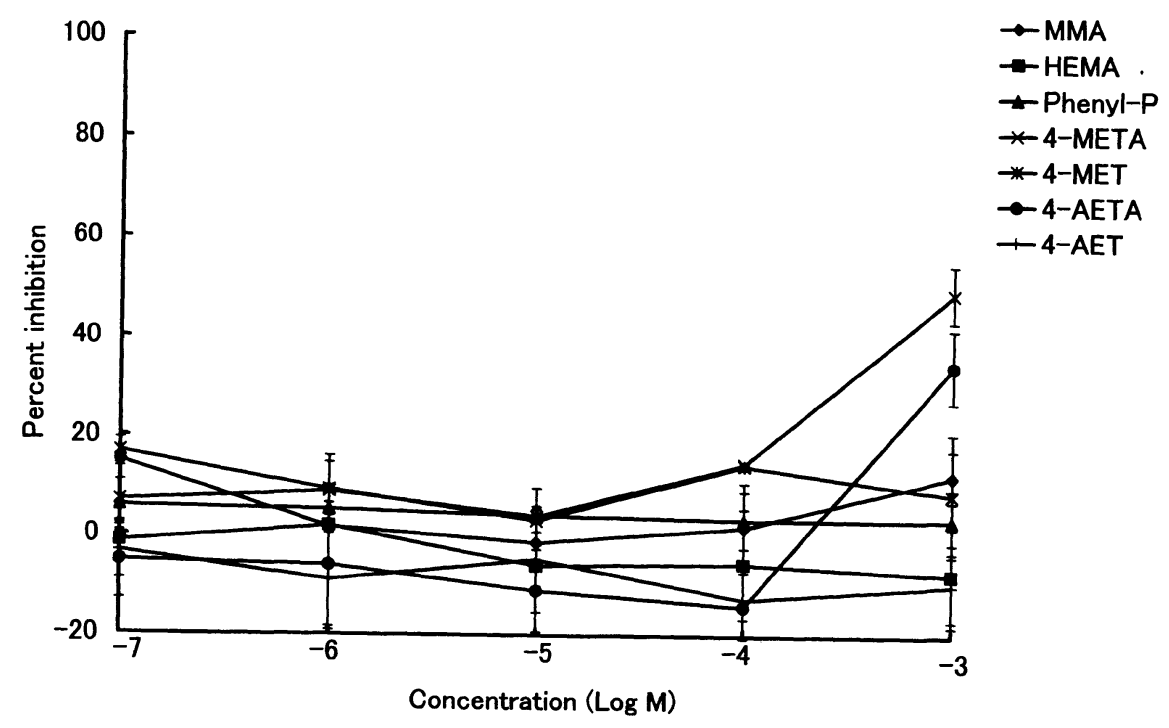

Fig. 3 a

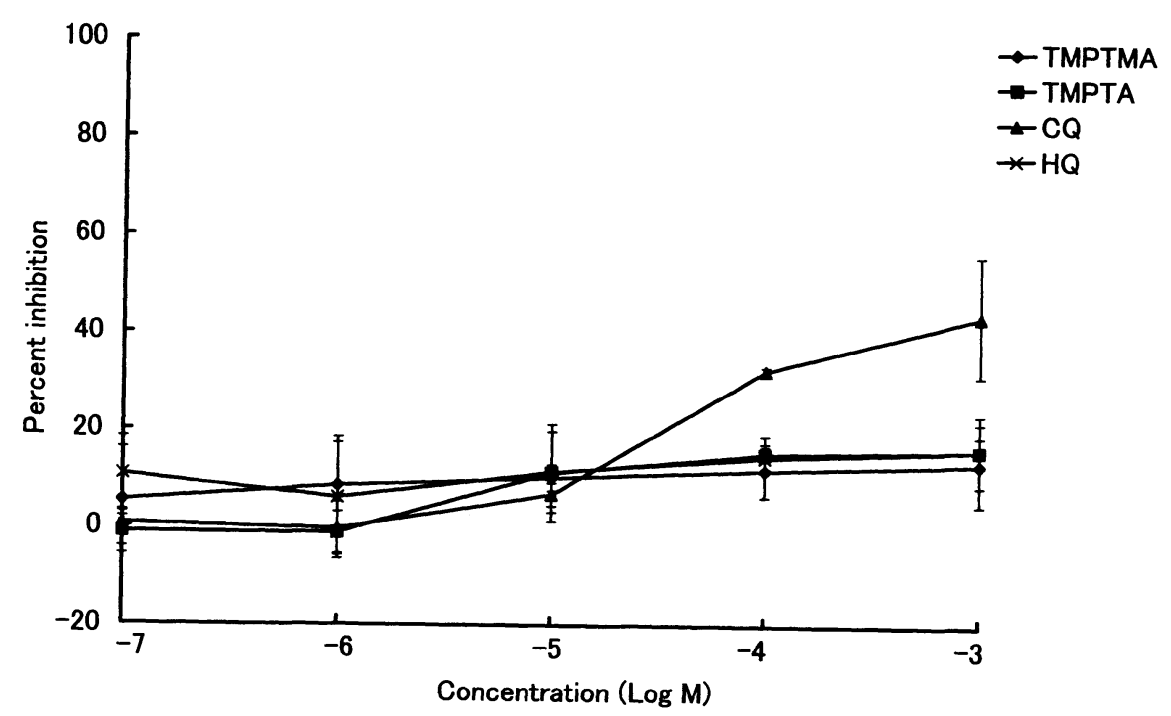

Fig. 3 b 


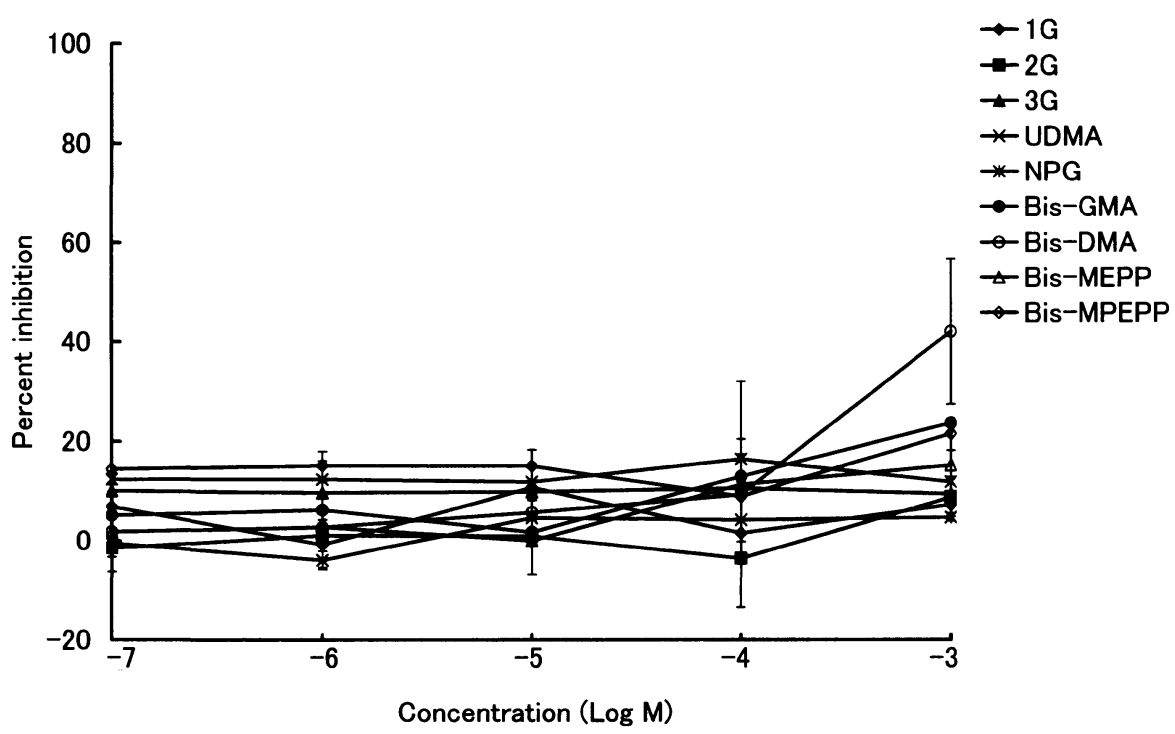

Fig. $3 \mathrm{c}$

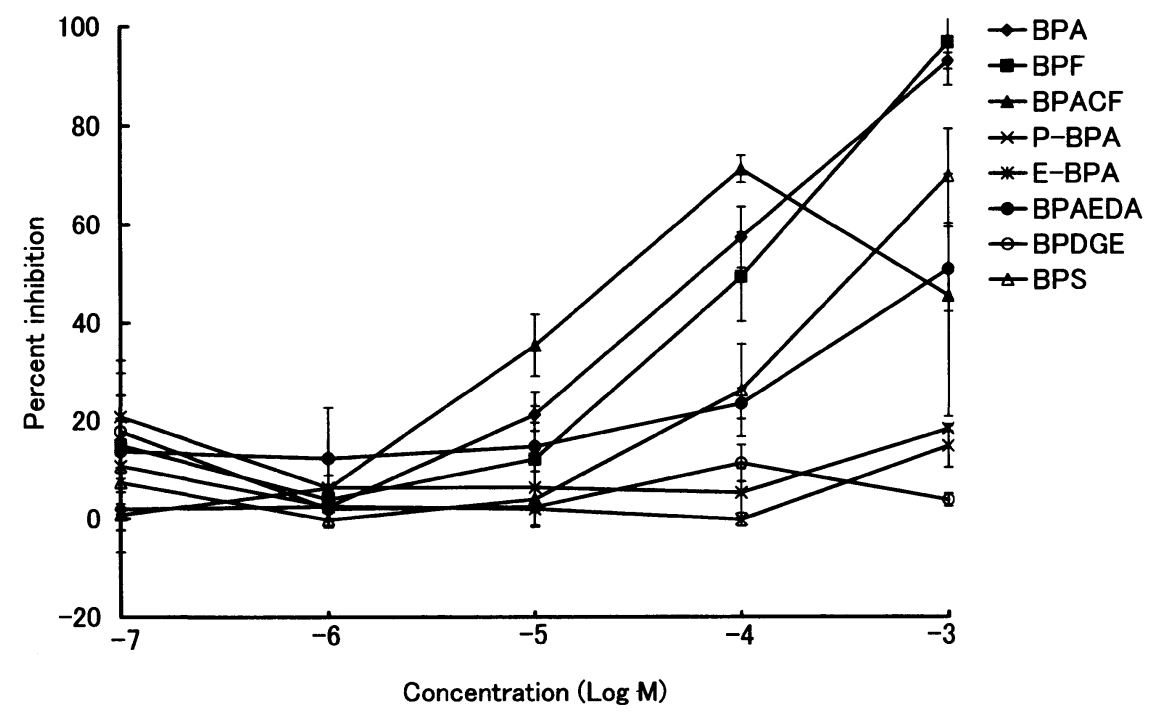

Fig. $3 \mathrm{~d}$

Fig. 3 Competition binding curves of chemicals against a human recombinant estrogen receptor $\alpha$ /fluorescent ligand complex (ER-ES1 complex).

Chemicals were added to the screening buffer in doses ranging from $10^{-7}$ to $10^{-3} \mathrm{M}$ with ER-ES1 complex for $60 \mathrm{~min}$ at room temperature $\left(25^{\circ} \mathrm{C}\right)$ followed by measurement of fluorescence polarization. Polarization findings were converted to percent inhibition. 

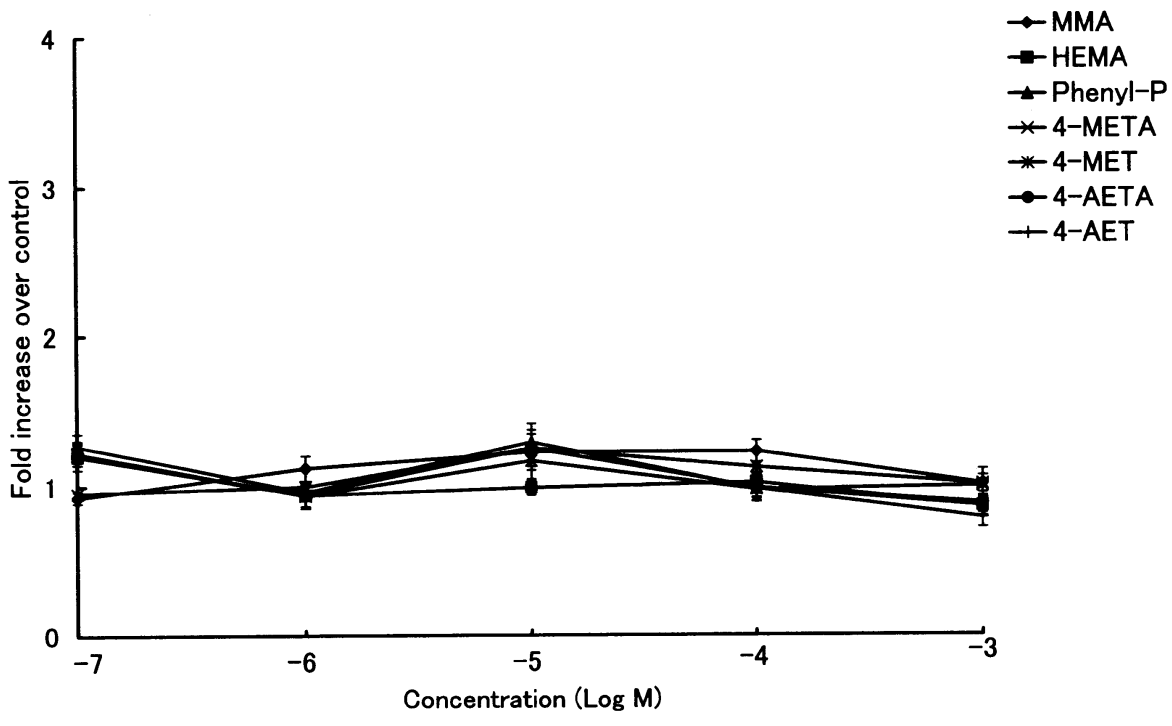

Fig. 4 a

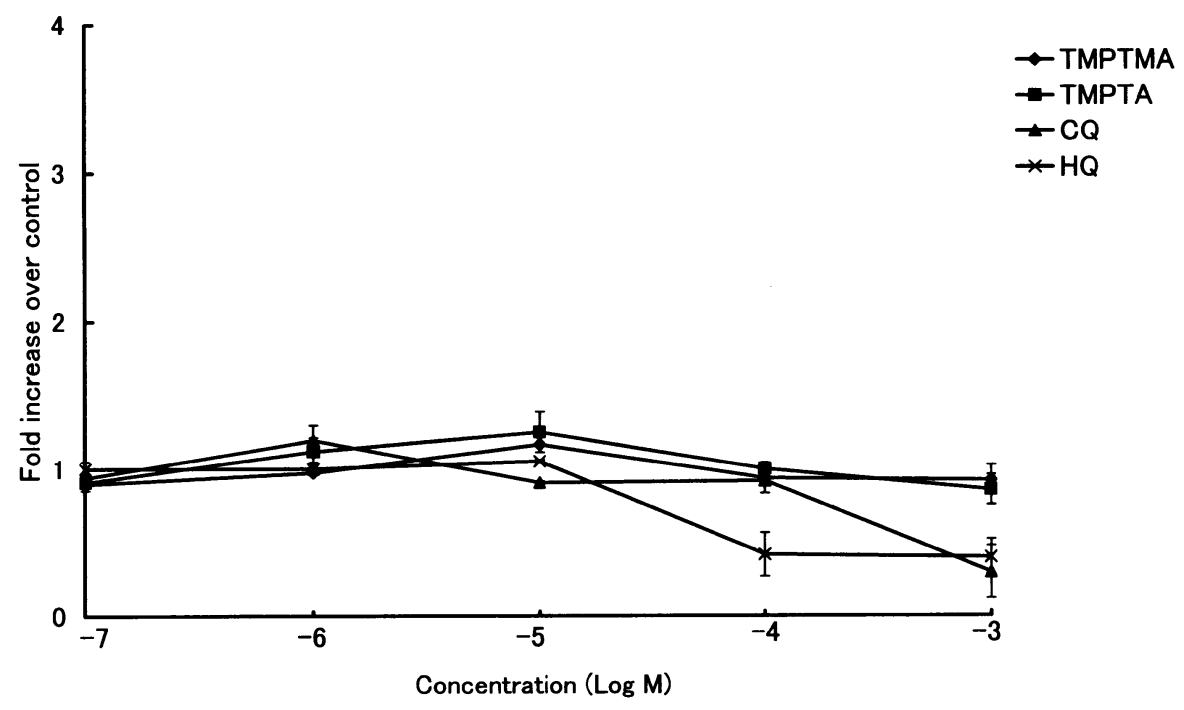

Fig. 4 b 


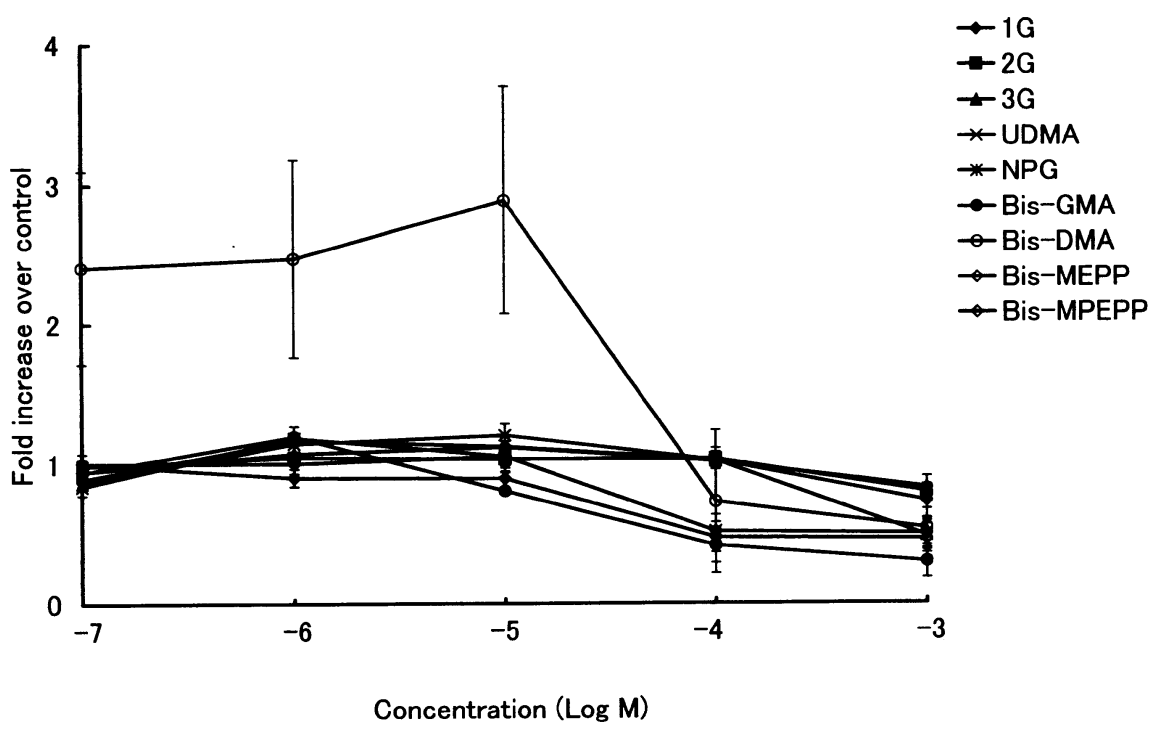

Fig. 4 c

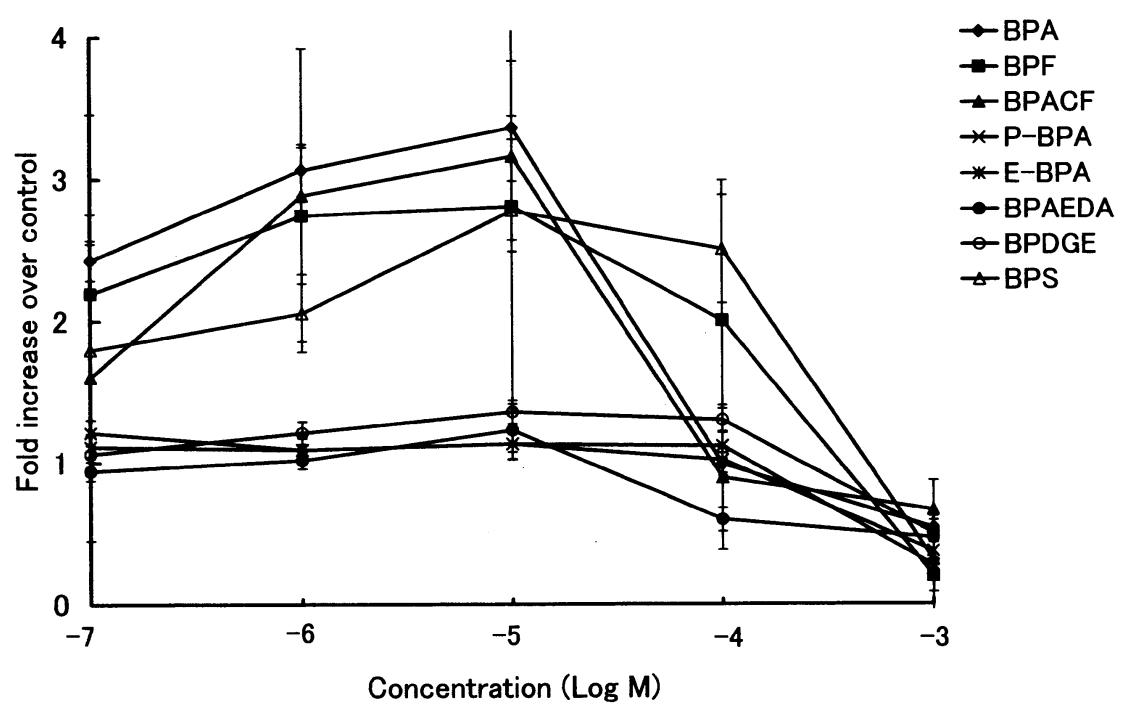

Fig. 4 d

Fig. 4 Dose-response curves of chemicals.

Chemicals were added to MCF-7 cells stock in doses ranging from $10^{-7}$ to $10^{-3} \mathrm{M}$. Following $144 \mathrm{hr}$ incubation, the cultures were assayed for neutral red. DMSO as served the control. The absorbence was measured with a microplate reader equipped with a $540 \mathrm{~nm}$ filter. The readings were averaged and the results expressed as fold increase over control. 
at concentrations of $10^{-4}$ and $10^{-3} \mathrm{M}$, and significantly increased the percent inhibition in comparison with BPACF and BPS at $10^{-3} \mathrm{M}(\mathrm{p}<0.05)$. BPACF increased the percent inhibition and showed the highest percent inhibition at concentrations of $10^{-4}$ $(71 \pm 2.8 \%)(p<0.01)$. BPS increased the percent inhibition at concentrations of $10^{-3}$ M. The remaining 24 chemicals did not show similar effects at the concentrations tested.

The effects of the test chemicals on the proliferation of MCF-7 cells are shown in Figs. 4 a-d. BPA, BPACF and Bis-DMA significantly increased MCF-7 cell growth at concentrations of $10^{-7}, 10^{-6}$ and $10^{-5} \mathrm{M}$, compared with the control $(\mathrm{p}<0.01)$. BPF and BPS significantly increased MCF-7 cell growth at concentrations of $10^{-7}, 10^{-6}$, $10^{-5}$ and $10^{-4} \mathrm{M}$, compared to the control $(\mathrm{p}<0.01$ ). BPA, BPACF and Bis-DMA were cytotoxic at $10^{-4} \mathrm{M}$ and above, while BPF and BPS were cytotoxic between $10^{-4}$ and $10^{-3} \mathrm{M}$. The remaining 23 chemicals did not increase MCF-7 cell growth at the concentrations tested, while Bis-GMA, Bis-MEPP, Bis-MPEPP, UDMA, HQ, CQ, P-BPA, E-BPA, BPAEDA and BADGE were cytotoxic at $10^{-4} \mathrm{M}$ and above.

\section{DISCUSSION}

The estrogenic activities of chemicals for dental use and BPA-related chemicals were tested by three in vitro bioassays. BPA, BPF and BPACF induced $\beta$-galactosidase activity by the yeast two-hybrid system, and BPA, BPF, BPACF, and BPS increased the percent inhibition by the fluorescence polarization system, while the remaining chemicals did not show such activity at the concentrations tested. In addition to BPArelated chemicals that were estrogenic in the above two assays, Bis-DMA also significantly increased MCF-7 cell growth in the E-screen test, but the remaining chemicals did not. In this study, a $\beta$-galactosidase activity above 0.1 , more than 50 percent inhibition and a 1.5 -fold increase in cell growth over the control were considered estrogenic activity, respectively. The yeast two-hybrid system appears to be less sensitive than the other assays.

$\mathrm{BPA}, \mathrm{BPF}$ and BPACF were estrogenic in the yeast two-hybrid system. The yeast two-hybrid system is based on the ligand-dependent interaction between a nuclear hormone receptor and a coactivator. Using the activation domain derived from the yeast transactivator GAL4, strong $\beta$-galactosidase activity could be obtained ${ }^{7)}$. However, the conventional yeast assay, the yeast estrogen screen (YES) is cost-effective and sensitive, but requires special processing to detect estrogenic activity ${ }^{11)}$. However, Nishikawa et al. ${ }^{7)}$ reported that transcriptional activation of ER in YES might occur by spurious interaction with unrelated factors in yeast, resulting in reduced reliability. Coldham et $a l .{ }^{12)}$ reported that BPA showed a dose-related estrogenic effect in YES at $10^{-7} \mathrm{M}$. Thus, based on the present findings, the yeast two-hybrid system appears to be less sensitive than the YES system. This may be due to the short-term incubation of chemicals with recombinant yeasts $(4 \mathrm{hr}$ vs. overnight). $\beta$-galactosidase activity can increase with overnight incubation. However, the longer exposure to chemicals may affect the growth and viability of yeast. The cytotoxicity of the 
chemicals can be evaluated after $4 \mathrm{hr}$ incubation with yeast. Despite of noncytotoxicity of BPACF at the concentrations tested, BPACF did not induce $\beta$ galactosidase activity at concentrations of $10^{-4} \mathrm{M}$ and above, which suggests if could be specifically estrogenic around $10^{-4} \mathrm{M}$.

In the present study, we adopted a new estrogen/ER competition binding assay and used it for the rapid screening of endocrine disrupting chemicals for ER binding activity. This assay uses fluorescence polarization to monitor the displacement of a high-affinity fluorescent ligand from purified recombinant human ER. Furthermore, this assay can be run at physiological temperatures, requires less than half a day to complete, and involves no radioactivity ${ }^{8)}$. BPA, BPF, BPACF and BPS showed estrogenic activity by the fluorescence polarization system, but the remaining chemicals did not. The EC50 values for each chemical were calculated by non-linear leastsquares regression and the relative binding affinities (RBAs) for each chemical in relation to that of the natural ligand E2 were also calculated. This RBAs value for BPA is similar to those reported by Kuiper et al. ${ }^{13)}$ and Perez et $a l .{ }^{1)}$ in an estrogen/ER competition binding assay using $\left[{ }^{125} \mathrm{I}\right]$-estradiol and $\left[{ }^{3} \mathrm{H}\right]$-estradiol, but is significantly lower than that observed by Waller et $a .^{14)}$ using the CoMFA/3D-QSAR model. BPACF showed the highest percent inhibition at $10^{-4} \mathrm{M}$, as in the yeast two-hybrid system. This is suggested to be due to the same reason described above.

We also used the E-screen test described by Villalobos et $a l^{9)}$ This assay compares the cell yield between cultures of breast tumor-derived MCF-7 cells treated with estradiol and cultures treated with different chemicals. BPA, BPF, BPACF, Bis-DMA and BPS showed estrogenic activity by MCF-7 cell growth in the E-screen test, but the remaining chemicals did not. We compared the estrogenic activities of these chemicals to those reported by Perez et al. ${ }^{1)}$ BPA, BPF and Bis-DMA significantly increased MCF-7 cell growth at $10^{-6} \mathrm{M}$, as they reported. However, in the present study, these chemicals increased proliferation approximately three-fold relative to the control, which is about half that reported by Perez et al. ${ }^{1)}$ Furthermore, they reported that BPAEDA and BADGE showed estrogenic activity at higher concentrations. This may reflect the ability of MCF-7 cells to proliferate in the presence of estrogens. The BUS cell stocks used by Perez et al. ${ }^{1)}$ might be more sensitive than the ATCC cell stocks used in the present study, and from other sources could lead to different results. BisDMA significantly increased MCF-7 cell growth at $10^{-7} \mathrm{M}$ over the control, but BisGMA, Bis-MEPP, Bis-MPEPP did not. Matsuzawa et al. ${ }^{15)}$ reported that Bis-GMA and TEGDMA did not have estrogenic activity in the E-screen test of MCF-7 cells. However, Nathanson et al. ${ }^{16)}$ reported in an in vitro study that Bis-GMA significantly increased MCF-7 cell growth at $10^{-8} \mathrm{M}$, and suggested that it had an estrogenic effect.

There were occasional discrepancies between the assays. For example, Bis-DMA did not show any estrogenic activity, and BPA, BPF, BPACF and BPS did not show estrogenic activity at concentrations of $10^{-7}, 10^{-6}$ and $10^{-5} \mathrm{M}$ using the yeast twohybrid system and fluorescence polarization system, while they did show such activity in the E-screen test. The yeast two-hybrid system and fluorescence polarization system are used to examine the interaction between ER- $\alpha$ and coactivators, and estro- 
gen/ER- $\alpha$ competition binding, respectively. Thus, only ER- $\alpha$ binding is required to evaluate estrogenic activity. The cloning of a second estrogen receptor, ER- $\beta$, has recently been reported ${ }^{17)}$, it is also present, together with ER- $\alpha$, in some human breast cancer cell lines ${ }^{18)}$. The proliferation of MCF-7 cells in response to endocrine disrupting chemicals could be based not only on ER- $\alpha$ but also on the ER subtype. Another possible factor in this discrepancy, as with Bis-DMA noted above, is that cellular enzymatic systems may play a role and enhance estrogenic activity. Interestingly, BisDMA showed estrogenic activity in the E-screen test, but not using the yeast twohybrid system or fluorescence polarization system. Soderholm et al. ${ }^{19)}$ pointed out, under clinical conditions, that esterase present in saliva could break ester linkages. If the ester linkage of Bis-DMA is attacked by esterase, BPA might be released. It is known that esterase or hydrolase activities are in mammalian serum ${ }^{20)}$, as a result, Bis-DMA might be metabolized to estrogenic metabolites.

Despite the usefulness of these methods for detecting estrogenicity, they also have limitations. For example, in the two-hybrid system, the yeast cells are more robust than mammalian cells and have a cell wall. Some chemicals may not be able to permeate through such a cell wall, which would complicate any interpretation of the results. In the fluorescence polarization system, a decrease in the percent inhibition above $20 \%$ was observed for Bis-GMA, BisMPEPP, Bis-DMA, 4-META, 4-AETA, CQ and BPAEDA at concentrations higher than $10^{-4} \mathrm{M}$. Although the reasons for this result are not clear, precipitation and coloring of the screening buffer occurred at this concentration. This phenomenon, or staining by chemicals, might interfere with the system. Bis-GMA, Bis-MEPP, Bis-MPEPP, Bis-DMA, UDMA, HQ, CQ, P-BPA, E-BPA, BPAEDA and BADGE were cytotoxic at concentrations ranging from $10^{-5}$ to $10^{-3} \mathrm{M}$. When a chemical was cytotoxic to MCF-7 cells, the E-screen could not be used.

Previous studies have shown that modern dental materials contain many different monomers and additives. MMA, HEMA, Phenyl-P, 4-META, 4-MET, 4-AETA 4-AET, TMPTMA, TMPTA, HQ, CQ, 1G, 2G, 3G, UDMA, NPG, Bis-GMA, Bis-DMA, BisMEPP and Bis-MPEPP have been widely used as major oligomers, monomers, photoabsorbers, inhibitors and diluent oligomers in various resin composites and sealants $^{21-24)}$. Several studies have shown that resin composite fillings might cause pulp inflammation ${ }^{25-31)}$. Stanley et al. ${ }^{25)}$ reported that composites could be considered toxic. Baume et $a l .{ }^{26)}$ stated that this pulp reaction to composites was mild if there was 1 $\mathrm{mm}$ or more remaining dentin. Extracts of resin composites, dentin bonding agents and various composite ingredients have been shown to be cytotoxic, genotoxic and mutagenic in several in vitro studies. Yoshii ${ }^{27)}$ examined the relationship between the structure and cytotoxicity of monomers used in dental resin materials, and reported that monomers could be ranked in terms of cytotoxicity as BisGMA $>$ UDMA $>$ NPG $>1 \mathrm{G}>2 \mathrm{G}>3 \mathrm{G}>4$ META $>$ HEMA $>$ MMA. Furthermore, Geurtsen et $a l^{28)}$ examined the cytotoxic effects (ED50 concentrations) of 35 monomers or additives in commercial dental resin composites. Among co-monomers, initiators and coinitiators, Bis-GMA, UDMA, Bis-DMA, DMBZ and DMDTA had severe cytotoxic effects, while HEMA, BEMA, CQ, DMPT and DMAPE had moderate cytotoxic 
effects. In addition, Schweikl et $a{ }^{29)}$ reported that MMA, HEMA and glutaraldehyde may promote mutagenicity, and suggested that glutaraldehyde and glutaraldehydecontaining bonding agents were clearly mutagenic. In a related study, a dental assistant developed allergic contact dermatitis caused by BPA-containing composites based on epoxy dimethacrylate ${ }^{30)}$. Furthermore, benzoyl peroxide is well known to be a tumor promoter, and is cytotoxic and allergenic ${ }^{31}$. In the studies described above, the side effects of dental materials have been widely investigated. Recently, resin-based dental restorative materials have been targeted as potential sources of xenoestrogenicity, especially BPA, which has been shown to have deleterious side effects ${ }^{32)}$. However, estrogenic activity has not been considered as a side effect of dental materials. Thus, estrogenicity may need to be considered in future studies of the biological safety of dental materials, once an effective screening method is established.

Since Olea et $a l^{32}{ }^{32}$ reported the possibility that BPA may be released from dental sealants, many studies have examined this release under various conditions and tried to detect BPA released from commercial resin-based restorative materials. While Lewis et $a l^{33)}$ detected the presence of BPA and Bis-DMA in commercial resin-based restorative materials, the levels of these compounds were much lower than those reported by Olea et al. ${ }^{32}$ Indeed, several studies have reported that BPA is not released from commercial resin-based restorative materials. The use of an aqueous solution for studying BPA release resulted in no release of BPA, since BPA does not dissolve well due to its hydrophobic nature ${ }^{34)}$. However, the selection of an aqueous solution is reasonable clinically, and any bioassay of estrogenic activity should consider the oral environment. We tested the estrogenic activity of extracts from Bis-GMA-based sealants under four conditions (heptanes, 50\% ethyl alcohol, $4 \%$ acetic acid and artificial saliva). In all of the extracts, BPA was not detected by HPLC and showed no estrogenic activity by the two-hybrid system ${ }^{35)}$. However, BPA appears to be more estrogenic in animal studies than predicted by in vitro assays. BPA was examined for its effect on accessory reproductive organs and daily sperm production in male offspring of mice fed this chemical during pregnancy ${ }^{36)}$. From days 11-17 of gestation, female mice were fed an average of $2 \mathrm{ng} / \mathrm{g}$ body weight $(2 \mathrm{ppb}$ ) of BPA (dissolved in oil), and this $2 \mathrm{ng} / \mathrm{g}$ dose of BPA permanently increased the size of the preputial glands, but reduced the size of the epididymides ${ }^{37)}$. More recently, Mariotti et al. ${ }^{38)}$ reported the estrogenicity of Bis-GMA in vivo using the uterotropic assay. The normalized wet weights of uteri from ovariectomized mice receiving a high dose $(100 \mu \mathrm{g} / \mathrm{kg})$ of Bis-GMA or estradiol were significantly greater ( $29 \%$ and $786 \%$ greater, respectively) than those of the ovariectomized control.

Little is known about whether dental materials or BPA itself accumulate in the human body or how they are metabolized. The metabolic fate of an orally administrated dose of $\left[{ }^{14} \mathrm{C}\right]$-BPA has been studied in rats. Over an 8-day period, $28 \%$ and $56 \%$ of $\left[{ }^{14} \mathrm{C}\right]$-BPA was excreted in the urine and feces, respectively, and no $\left[{ }^{14} \mathrm{C}\right]-\mathrm{BPA}$ residues could be detected in the carcass after 8 days $^{39)}$. Clime et al. ${ }^{40,41)}$ orally administrated $\left[{ }^{14} \mathrm{C}\right]$-BADGE to mice and found that it was rapidly excreted; $80 \%$ and $11 \%$ of the administered $\left[{ }^{14} \mathrm{C}\right]$-BADGE was eliminated in the feces and the urine, 
respectively, 0-3 days after a single oral dose. These findings suggest that a chemical like BADGE is not easily absorbed from the gastrointestinal tract. Hikage et al. ${ }^{42)}$ demonstrated that the cytotoxicity of various dental resin monomers decreased in the presence of a rat liver S9 mix containing cytochrome $\mathrm{P} 450$ enzymes. The systemic behavior of dental materials and other BPA-related chemicals remains unclear and needs further investigation.

Thus, in the early stage of material research and development, it is important to clarify the estrogenic activity and structure/xenoestrogenicity relationship of chemicals intended for dental use. Estrogenic activity was initially assessed by the subcutaneous administration of chemicals to ovariectomized rats that were then observed for the onset of estrus ${ }^{43)}$. It soon became apparent that diphenyl and diphenyl methane derivatives and stilbene derivatives containing two hydroxyl groups in the para positions were estrogenic ${ }^{44-48}$. Among the BPA related chemicals tested in this study, BPA, BPF, BPACF, Bis-DMA and BPS showed estrogenic activity. Perez et al. ${ }^{1)}$ reported that diphenylalkanes, which have two terminal hydroxyl groups, were assayed to determine the nature of the para position: either free (BPA and BPF) or ether or ester bonds. Ester derivatives of diphenylalkanes (BPACF and Bis-DMA) were estrogenic, in contrast to some with ether substituents at the terminal $-\mathrm{OH}$, such as (Bis-GMA, P-BPA and E-BPA), which showed no estrogenic activity in the E-screen test. Moreover, BPS showed weak estrogenic activity although its chemical structure is not similar to those of the diphenylalkanes. BPS consists of two phenolic rings with two oxidant chains joined through a bridging sulfur. A chemical structure carry two terminal hydroxyl groups in the para-position could be estrogenic. MMA, HEMA, 1G, 2G, TEGDMA, UDMA, NPG, CQ, TMPTMA and TMPTA did not show estrogen activity in the present study. Estrogenicity may be related to chemical structures bearing benzene rings, since chemicals without benzene rings did not show estrogenic activity ${ }^{49)}$. The first studies of active compounds containing only one benzene ring, such as para-hydroxy propenyl benzene and some alkylphenolic compounds, have been reported ${ }^{50,51}$. Some phthalate esters containing only one benzene ring have also been shown to exhibit extremely weak estrogenicity ${ }^{52)}$. Phenyl-P, 4-META, 4MET, 4-AETA, 4-AET and HQ, which have only one benzene ring, but not the structure described above, did not show estrogenic activity.

In conclusion, the present findings show that BPA and some BPA-related chemicals (Bisphenol-F, Bisphenol-A-bischloroformate, Bisphenol-S) were estrogenic by three in vitro bioassays, while no related chemicals, except Bisphenol-A-dimethacrylate, were estrogenic in vitro. Bis-DMA based dental materials are reportedly no longer manufactured $^{53)}$. Of the chemicals tested in the present study, the diphenylalkanes that carry two terminal hydroxyl groups in the para-position, either free (BPA and $\mathrm{BPF}$ ) or as ester derivatives (BPACF and Bis-DMA), and those with two phenolic rings with two oxidant chains joined through a bridging sulfur (BPS), were estrogenic. However, it is not sufficient merely to determine that they are estrogenic. Additional information, together with in vivo and epidemiological examinations, are required. Furthermore, the accumulation of information on various aspects of 
materials science and estrogenicity could lead to the development of new chemicals and a possible reconsideration of chemicals currently used in dental applications.

\section{ACKNOWLEDGEMENTS}

This work was partially supported by a Grant-in-Aid for General Scientific Research (A) (1) (No.1130704) and Science Propulsion Enterprise from the Ministry of Education, Science, Sports and Culture of Japan.

The authors thank Professor T. Nishihara and Associate Professor J. Nishikawa at the Graduate School of Pharmaceutical Sciences, Osaka University, for helpful suggestions about the manuscript. The authors also thank the members of the Department of Biomaterials for their kind advice and help. Part of this study was carried out using the Institute of Dental Research, Osaka Dental University.

\section{REFERENCES}

1) Perez, P., Pulgar, R., Olea, F., Villalobos, M., Rivas, A., Metzler, M., Pedraza, V. and Olea, N.: The estrogenicity of bisphenol A-related diphenylalkanes with various substituents at the central carbon and the hydroxy groups, Environ Health Perspect 106 : 167-174, 1998.

2) Sonnenschein, C. and Soto, A. M.: An updated review of environmental estrogen and androgen mimics and antagonists, J Steroid Biochem Mol Biol 65 : 143-150, 1998.

3) Jobling, S., Reynolds, T., White, R., Parker, M. G. and Sumpter, J. P.: A variety of environmentally persistent chemicals, including some phthalate plasticizers, are weakly estrogenic, Environ Health Perspect 103 : 582-587, 1995.

4) Gebelein, C. G.: Polymer science and technology, Biomedical and dental applications of polymers, Plenum Press, New York and London, 1981. pp.317-335.

5) The dental materials and devices research committee: A provisional report on the relation of chemicals based on Bisphenol-A, which is doubted to be estrogen mimics, to dental materials, $J$ J Dent Mater $18: 302-331$, 1999. (in Japanese)

6) Zacharewski, T.: Identification and assessment of endocrine disruptors: limitations of in vivo and in vitro assays. Environ Health Perspect $106: 577-82,1998$.

7) Nishikawa, J., Saito, K., Goto, J., Dakeyama, F., Matsuo, M. and Nishihara, T.: New screening chemicals with hormonal methods for activities using interaction of nuclear hormone receptor with coactivator, Toxicol Appl Pharmacol 154:76-83, 1999.

8) Bolger, R., Wiese, T. E., Evrin, K., Nestich, S. and Checovich, W.: Rapid screening of environmental chemicals for estrogen receptor binding capacity, Environ Health Perspect 106 : 551-557, 1998.

9) Villalobos, M., Olea, N., Brotons, J. A., Olea-Serrano, M. F. and Ruiz de Almodovar, J. M.: The E-screen assay: a comparison of different MCF-7 cell stocks, Environ Health Perspect 103 : 844-850, 1995.

10) Borenfreund, E., Babich, H. and Martin-Alguacil, N.: Rapid chemosensitivity assay with human normal and tumor cells in vitro, In Vitro Cell Dev Biol $26: 1030-1034,1990$

11) Arnold, S. F., Robinson, M. K., Notides, A. C., Guillette, L. J. Jr. and McLachlan, J. A.: A yeast estrogen screen for examining the relative exposure of cells to natural and xenoestrogens, Environ Health Perspect 104 : 544-548, 1996.

12) Coldham, N. G., Dave, M., Sivapathasundaram, S., McDonnell, D. P., Connor, C. and Sauer, M. J.: Evaluation of a recombinant yeast cell estrogen screening assay, Environ Health Perspect 105 : 734-742, 1997.

13) Kuiper, G. G., Carlsson, B., Grandien, K., Enmark, E., Haggblad, J., Nilsson, S. and 
Gustafsson, J.: A comparison of the ligand binding specificity and transcript tissue distribution of estrogen receptors alpha and beta, Endocrinology $138: 863-870,1997$.

14) Waller, C. L., Oprea, T. I., Chae, K., Park, H. K., Korach, K. S., Laws, S. C., Wiese, T. E., Kelce, W. R. and Gray, L. E.: Ligand-based identification of environmental estrogens, Chem Res Toxicol 9 : 1240-1248, 1996.

15) Matsuzawa, M., Kawata, A., Kurata, S., Uchimura, N. and Kawase, T.: In vitro study of composites released from fissure sealants and their estrogenicity, in Proceeding of the 77th general session of the IADR, March 1999, p.436.

16) Nathanson, D., Lertpitayakun, P., Lamkin, M.S., Edalatpour, M. and Chou, L. L.: In vitro estrogenic activity of leachable components from dental sealants and composites, in Proceeding of the 77th general session of the IADR, March 1999, p.194.

17) Kuiper, G. G., Enmark, E., Pelto-Huikko, M., Nilsson, S. and Gustafsson, J. A.: Cloning of a novel receptor expressed in rat prostate and ovary, Proc Natl Acad Sci USA 93 : 5925$5930,1996$.

18) Vladusic, E. A, Hornby, A. E., Guerra-Vladusic, F. K, Lakins, J. and Lupu, R.: Expression and regulation of estrogen receptor beta in human breast tumors and cell lines, Oncol Rep $7:$ 157-67, 2000.

19) Soderholm, K. J. and Mariotti, A.: BIS-GMA-based resins in dentistry: are they safe?, JADA 130 : 201-209, 1999.

20) Butte, W. and Kemper, K.: A spectrophotometric assay for pyrethroid-cleaving enzymes in human serum, Toxicol Lett $107: 49-53,1999$.

21) Atsuta, M., Nakabayashi, N. and Masuhara, E.: Hard methacrylic polymers II -copolymers of methyl methacrylate and 2,2-di (4-methacryloxyphenyl) propane-, J Biomed Mater Res 5 : 183-195, 1971.

22) Atsuta, M., Nakabayashi, N. and Masuhara, E.: Hard methacrylic polymers II -copolymers of ethylene or trioxyethylene dimethacrylate with 2, 2-di (4-methacryloxyphenyl) propane, J Biomed Mater Res 6 : 479-487, 1972.

23) Kubota, T.: Nihon tokkyo 1091732, US patent 4134930, 1979.

24) Philips, R. W.: Skinner's science of dental Materials, 10th ed., W. B Sauders Co., Philadelphia, 1996. pp.273-313.

25) Stanley, H. R., Swerdlow, H. and Buonocore, M. G.: Pulp reactions to anterior restorative materials, Am $J A J 75: 132-141,1967$.

26) Baume, L. J. and Fiore-Donno, G.: Response of the human pulp to a new restorative material, $A m J A J 76$ : 1016-1022, 1967.

27) Yoshii, E.: Cytotoxicity effects of acrylates and methacrylates: relationships of monomer structures and cytotoxicity, J Biomed Mater Res 37 : 517-524, 1997.

28) Geurtsen, W., Lehmann, F., Spahl, W. and Leyhausen, G.: Cytotoxicity of 35 dental resin composite monomers/additives in permanent 3T3 and three human primary fibroblast cultures, J Biomed Mater Res 41 : 474-480, 1998.

29) Schweikl, H. and Schmalz, G.: Glutaraldehyde-containing dentin bonding agents are mutagens in mammalian cells in vitro, $J$ Biomed Mater Res 36 : 284-288, 1997.

30) Carmichael, A. J., Gibson, J.J. and Walls, A. W.: Allergic contact dermatitis to bisphenol-A-glycidyldimethacrylate (BIS-GMA) dental resin associated with sensitivity to epoxy resin, Br Dent $J 183: 297-298,1997$.

31) Gopalakrishna, R., Gundimeda, U., Anderson, W. B., Colburn, N. H. and Slaga, T. J.: Tumor promoter benzoyl peroxide induces sulfhydryl oxidation in protein kinase C: its reversibility is related to the cellular resistance to peroxide-induced cytotoxicity, Arch Biochem Biophys 363 : 246-258, 1999.

32) Olea, N., Pulgar, R., Perez, P., Olea-Serrano, F., Rivas, A., Novillo-Fertrell, A., Pedraza, V., Soto, A. M. and Sonnenschein, C.: Estrogenicity of resin-based composites and sealants used in dentistry, Environ Health Perspect 104 : 298-305, 1996.

33) Lewis, J. B., Rueggeberg, C. A., Lapp, C. A., Ergle, J. W. and Schuster, G. S.: Identification and characterization of estrogen-like components in commercial resin-based dental 
restorative materials, Clin Oral Invest $3:$ 107-113, 1999.

34) Noda, M., Komatsu, H. and Sano, H.: HPLC analysis of dental resin composites components, J Biomed Mater Res 47 : 374-378, 1999.

35) Kawaguchi, M., Hashimoto, Y., Moriguchi, Y., Oshima, H., Nakamura, M. and Miyazaki, K.: Estrogenic activity of Bis-GMA-based sealants, in Proceeding of the 47th general session of the JADR, November 1999, p.86.

36) Nagel, S. C., vom Saal, F.S., Thayer, K. A., Dhar, M. G., Boechler, M. and Welshons, W. V.: Relative binding affinity-serum modified access (RBA-SMA) assay predicts the relative in vivo bioactivity of the xenoestrogens bisphenol $\mathrm{A}$ and octylphenol, Environ Health Perspect 105 : 70-76, 1997.

37) vom Saal, F. S., Cooke, P. S., Buchanan, D. L., Palanza, P., Thayer, K. A. Nagel, S. C., Parmigiani, S. and Welshons, W. V.: A physiologically based approach to the study of bisphenol A and other estrogenic chemicals on the size of reproductive organs, daily sperm production, and behavior, Toxicol \& Ind Health $14: 239-260,1998$.

38) Mariotti, A., Soderholm, K. J. and Johnson, S.: The in vivo effects of bisGMA on murine uterine weight, nucleic acids and collagen, Euro J Oral Sci 6 : 1022-1027, 1998.

39) Knaak, J. B. and Sullivan, L. J.: Metabolism of bisphenol-A in the rat, Toxicol Appl Pharmacol $8: 175-184,1966$.

40) Clime, I. J. G., Huston, D. H. and Stoydin, G.: Metabolism of the epoxy resin component 2,2-bis [4-(2,3-epoxypropoxy) phenyl] propane, the diglycidyl ether of Bisphenol A (DGEBPA) in the mouse. Part I. A comparison of the fate of a single dermal application and of a single oral dose of ${ }^{14} \mathrm{C}$-DGEBPA in the mouse, Xenobiotica $11: 391-399$, 1981.

41) Clime, I. J. G., Huston, D. H. and Stoydin, G.: Metabolism of the epoxy resin component 2,2-bis [4-(2,3-epoxypropoxy) phenyl] propane, the diglycidyl ether of Bisphenol A (DGEBPA) in the mouse. Part II. Identification of metabolites in urine and faeces following a single dose of ${ }^{14} \mathrm{C}-\mathrm{DGEBPA}$ in the mouse, Xenobiotica $11: 401-424,1981$.

42) Hikage, S., Sato, A., Suzuki, S., Cox, C. F. and Sakaguchi, K.: Cytotoxicity of dental monomers in the presence of S9 mix enzymes, Dent Mater $J 18: 76-86,1999$.

43) Cook, J. W., Dods, E. C. and Hewett, C. L.: Synthetic oestrusexciting compounds, Nature $131: 56-57,1933$.

44) Dods, E. C. and Lawson, W.: Synthetic oestrogenic agents without phenathrene uncleus, Nature 137 : 996, 1936.

45) Dods, E. C. and Lawson, W.: Simple aromatic oestrogenic compounds and methods of assay, Nature 139 : 627-628, 1937.

46) Dods, E. C., Fitzgerald M. E. and Lawson, W.: Estrogenic activity of some hydrocarbon derivatives of ethylene, Nature $140: 772,1937$.

47) Dods, E. C., Golberg, L., Lawson, W. and Robinson, R.: Estrogenic activity of certain synthetic compounds, Nature $141: 247-248,1938$.

48) Dods, E. C., Golberg, L., Lawson, W. and Robinson, R.: Estrogenic activity of alkylated stilbestrols, Nature $142: 34,1938$.

49) Routledge, E. J. and Sumpter, J. P.: Structural features of alkylphenolic chemicals associated with estrogenic activity, J Biol Chem $272: 3280-3288,1997$.

50) Dods, E. C. and Lawson, W.: Estrogenic activity of p-hydroxy prophenyl benzene, Nature 139 : 1068-1069, 1937.

51) Dods, E. C. and Lawson, W.: Molecular structure in relation to oestrogenic activity. Compounds without phenanthrene nucleus, Proc R Soc Lond B Biol Sc 125 : 222-232, 1938.

52) Harris, C. A., Henttu, P., Parker, M. G. and Sumpter, J. P.: The estrogenic activity of phthalate esters in vitro, Environ Health Perspect $105:$ 802-811, 1997.

53) ADA council on scientific affairs position statement: Estrogenic effects of Bisphenol-A lacking in dental sealants, 1998. 